\title{
FREQUENCY AND MORPHOLOGY OF BENIGN HISTOPATHOLOGICAL LESIONS IN TOTAL ABDOMINAL HYSTERECTOMY SPECIMENS.
}

\footnotetext{
1. MBBS

Demonstrator

University College of Medicine \& Dentistry

2. MBBS, FCPS

Assistant Professor Obstetrics \& Gynecology

Creek General Hospital.

United Medical \& Dental College, Karachi

3. MBBS, FCPS

Assistant Professor Obstetrics \&

Gynecology

Creek General Hospita

United Medical \& Dental College,

Karachi.
}

Correspondence Address:

Dr. Saba Pario

Assistant Professor

Obstetrics \& Gynecology at Creek General Hospital.

United Medical \& Dental College, Karachi.

drsabapario@gmail.com

Article received on:

19/01/2019

Accepted for publication:

26/05/2019

\begin{abstract}
Aisha Rashid ${ }^{1}$, Haniya Qamar², Saba Pario ${ }^{3}$
ABSTRACT: Objectives: To determine the frequency and morphology of different benign histopathological lesions in total abdominal hysterectomy specimens. Study Design: Descriptive cross-sectional study. Setting: Department of Pathology Fatima Jinnah Medical College. Period: From Jan 2015 to June 2015. Material \& Methods: The gross and histopathological findings of uterus and cervix in one hundred Total Abdominal hysterectomy specimens were studied. Non-probability, purposive sampling was done. Total abdominal hysterectomy specimens with or without salpingoophorectomy of patients aged between 20 to 70 years were included. While Total abdominal hysterectomy done in mentally retarded patients and for malignancies were excluded. Patient's data, presenting complaints and preoperative diagnosis was recorded on predesigned proforma. SPSS version 17 was used as an analytical tool. Results: Age of the patients ranged from $30-55$ years with $72 \%$ between $41-50$ years. The microscopic examination of the cervix revealed features of chronic cervicitis in $75 \%$ cases. The commonest neoplastic lesion was leiomyoma present in $66 \%$ of cases. Myometrium revealed foci of adenomyosis in $21 \%$ cases. Endometrial histology showed hyperplasia in $25 \%$ of cases(simple hyperplasia $20 \%$, cystic hyperplasia $4 \%$ and complex hyperplasia $1 \%$ ), hormonal imbalance in $21 \%$, pressure atrophy in $11 \%$, atrophic endometrium in $6 \%$, cystic atrophy in $2 \%$ while acute and chronic endometritis in $1 \%$ and $2 \%$ of cases respectively. Conclusion: The commonest cervical lesion was chronic cervicitis (75\%). The commonest benign neoplastic lesion was leiomyoma, present in $66 \%$ of cases. Other common pathologies on histology were hyperplasia in $25 \%$ of cases, adenomyosis and hormonal imbalance in $21 \%$ of cases each, pressure atrophy in $11 \%$, atrophic endometrium in $6 \%$ while endometritis (acute \& chronic ) in $3 \%$ of cases mainly. Histopathological examination of hysterectomy specimens helps to detect the exact cause and underlined pathology.
\end{abstract}

Key words: $\quad$ Adenomyosis, Hysterectomy, Leiomyoma, Uterus Benign Lesions.

Article Citation: Rashid A, Qamar H, Pario S. Frequency and morphology of benign histopathological lesions in total abdominal hysterectomy specimens. Professional Med J 2020; 27(3):481-486.

DOI: $10.29309 / T P M J / 2020.27 .3 .3156$

\section{INTRODUCTION}

Hysterectomy is a Greek word meaning surgical removal of uterus. ${ }^{1}$ Charles Clay was the pioneer of this procedure, in $1843 .^{2}$

Hystrectomy is undertaken for varying indications and is among those gynecological surgeries that are carried out very often all over the globe, to effectively cure many gynecological conditions or save life of women suffering from postpartum hemorrhage in case of obstetrical hystrectomy. ${ }^{3,4}$

Hystrectomy is a major surgical procedure enabling increased satisfaction and improved quality of life post-surgery despite its associated complications. ${ }^{5,6}$

According to literature by age of sixty around $20 \%$ of women had underwent surgical removal of uterus and almost $40 \%$ among them diagnosed with abnormal uterine bleeding. ${ }^{7}$ The expected life time prevalence of hystrectomy is $10 \%{ }^{8}$ High order parity, ailments, obesity, tobbaco intake, poverty and use of hormonal therapy are indicators related with greater probability of undergoing hystrectomy. ${ }^{9}$ Hysterectomy may be performed via abdominal or vaginal routes, depending on pathology, indication for undergoing procedure 
and surgeon's expertise..$^{8,10}$ It is considered important that women should be counseled by her health care provider in detail regarding available treatment modalities and alternate treatment options should be informed to involve her in decision making before undergoing such major surgical procedure. ${ }^{11}$

Hysterectomy is a major surgical procedure in terms of both morbidity and mortality. Major surgical complications during procedure and debility in recovery period after surgery were observed in $3 \%$ and $1 \%$ of women respectively. ${ }^{12}$ Minimally invasive procedures are now available as alternate option of hystrectomy but not widely used due to untrained staff, expenses and non availability in many health centers. ${ }^{13,14}$

Histopathological analysis of the hysterectomy specimens should be undertaken for justification of procedure and diagnostic purposes. ${ }^{15}$ This research was aimed to ascertain frequency and morphology of different benign histopathological lesions in TAH specimens.

\section{MATERIAL AND METHODS}

This Descriptive cross sectional study was conducted in department of Pathology of Fatima Jinnah Medical College/ Sir Ganga Ram Hospital, Lahore, from January 2015 till June 2015. Ethical approval was taken from Institutional Ethical committee.

Sample size of 100 specimens was calculated with $95 \%$ confidence level. $10 \%$ margin of error and taking expected percentage of adenomyosis i.e. $47 \%$ (least among both) morphology of different benign histpathological lesions in total abdominal hysterectomy specimens.

Non-probability, purposive sampling was done. Total abdominal hysterectomy specimens with or without salpingoophorectomy of patients aged between 20 to 70 years were included. While Total abdominal hysterectomy done in mentally retarded patients and Total abdominal hysterectomy (TAH) done for malignancies were excluded. Patient's data, presenting complaints and preoperative diagnosis was recorded on predesigned proforma.

The hysterectomy specimens were kept in $10 \%$ formal saline for fixation. Each specimen was comprehensively studied and obvious findings noted.3-4mmthickness sectionswere undertaken. Sections were processed in an automatic tissue processor through ascending grades of alcohol and cleared in xylene. Embedding was done in paraffin using L-shaped metal moulds. Each block was cut into multiple sections 3-4 micrometer thick on a rotary microtome. Sections were taken on albumenized slides. Haematoxylin and eosin staining was carried out on all sections. Histopathological examination of all sections was carried out under microscope.

\section{Data Analysis}

Statistical Package for social sciences software version 17 was utilized for performing statistical operations. Mean standard deviations for quantitative variable like age were calculated. Descriptive Analysis frequency and percentages were calculated for qualitative variables like benign conditions, i.e., leiomyoma, adenomyosis.

\section{RESULTS}

The ages of the women extended from 30-55 years who underwent hysterectomy. Maximum number of cases were between 41-50 years i.e 72. Mean age was 44.64 years with standard deviation of 4.52. The descriptive statistics of age of patients are given in Table-I.

The presenting complaints of the patients are given in Figure-1. The commonest presenting complaint was menorrhagia (58 cases, 58\%). The gross dimensions of uterus are expressed in Table-II. Most common benign lesion seen in total abdominal hysterectomy specimens was leiomyoma present in $66 \%$ cases. The incidence of leiomyomas was maximum in the age group 41-50 years, i.e. 45 cases.

Adenomyosis was present in $21 \%$ of hysterectomy specimens, and it was found to be maximum in the age group 41-50 years, i.e 13 cases, among 21 total cases of adenomyosis. Frequency of leiomyoma and adenomyosis is revealed in 
Table-III.

Table-IV shows distribution of age of patients who underwent total abdominal hystrectomy, leiomyoma's and adenomyosis in hysterectomy samples with respect to different age groups.

Regarding endometrial histology hyperplasia observed in $25 \%$ of cases (simple hyperplasia
$20 \%$, cystic hyperplasia $4 \%$ and complex hyperplasia $1 \%$ ), hormonal imbalance in $21 \%$, proliferative phase in $29 \%$, secretory phase in $2 \%$, late secretory phase in $1 \%$, pressure atrophy in $11 \%$, atrophic endometritis in $6 \%$, cystic atrophy in $2 \%$ while acute and chronic endometritis in $1 \%$ and $2 \%$ of cases respectively expressed in Figure-2.

\begin{tabular}{|l|c|c|c|c|}
\hline & Minimum & Maximum & Mean & Standard Deviation \\
\hline AGE (Years) & 30 & 55 & 44.64 & 4.52 \\
\hline
\end{tabular}

Table-I. Age distribution.

\begin{tabular}{|l|c|c|c|c|}
\hline Dimensions of Uterus & Minimum & Maximum & Mean & Standard Deviation \\
\hline Length of uterus & 7 & 18 & 11.67 & 2.217 \\
\hline Breadth of uterus & 4 & 14 & 7.7 & 2.3668 \\
\hline Width of uterus & 2 & 9 & 4.38 & 1.8424 \\
\hline
\end{tabular}

\begin{tabular}{|l|c|c|c|}
\hline & Present \% & Absent \% & Total \\
\hline Leiomyoma & 66 & 34 & 100 \\
\hline Adenomyosis & 21 & 79 & 100 \\
\hline
\end{tabular}

\begin{tabular}{|l|c|c|c|c|c|}
\hline & $\mathbf{3 0 - 4 0}$ years & $\mathbf{4 1 - 5 0}$ years & $\mathbf{7 5 0}$ years & TOTAL & P-value \\
\hline Number of patients & 18 & 72 & 10 & 100 & - \\
\hline Number of leiomyoma & 11 & 45 & 10 & 66 & $\begin{array}{c}0.289 \\
\text { Chi sq=2.483 }\end{array}$ \\
\hline Number of adenomyosis & 6 & 13 & 2 & 21 & $\begin{array}{c}0.362 \\
\text { Chi sq=2.033 }\end{array}$ \\
\hline
\end{tabular}

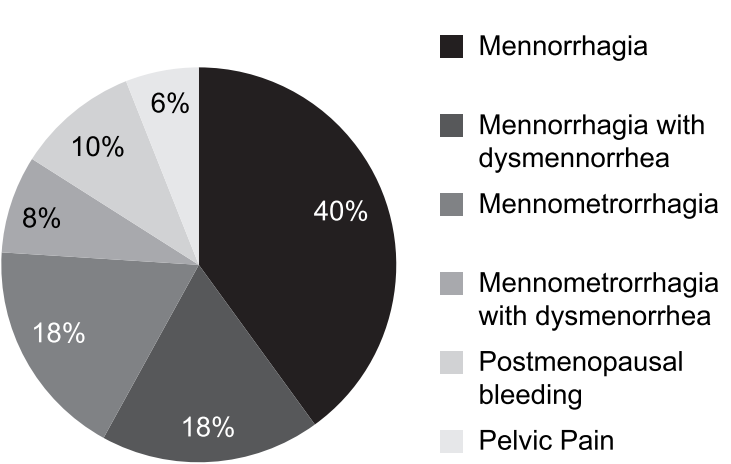

Figure-1. Presenting complaints of patients.

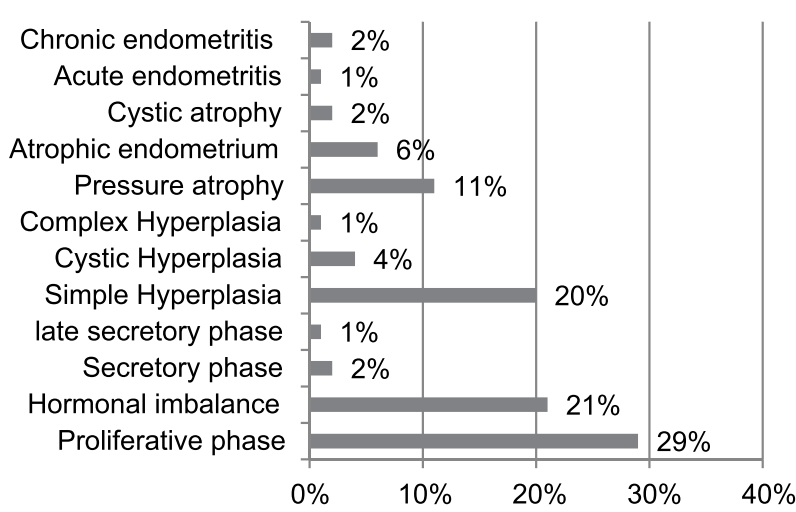

Figure-2. Distribution of endometrial changes. 


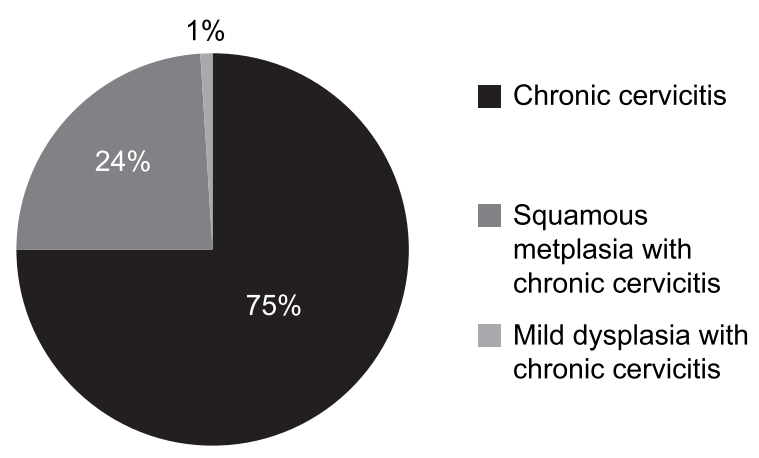

Figure-3. Histopathological changes in cervix.

Among cervical pathologies observed in total abdominal hysterectomy specimens, chronic cervicitis was the most common one, present in $75 \%$ cases. Squamous metaplasia with chronic cervicitis was present in $24 \%$ cases while mild dysplasia with chronic cervicitis was observed in one case only, graphical presentation of cervical pathologies shown in Figure-3.

\section{DISCUSSION}

Hysterectomy is considered definite treatment modality for various pelvic pathologies, it is second commonly done operation in females all over the world next to cesarean section. ${ }^{16}$

This is the procedure which really contributes to improving the quality of life of women. ${ }^{17}$

The ages of the women varied from 30 to 55 years who underwent hystrectomy, the maximum incidence of hysterectomy observed between 41 to 50 years, with a mean of 44.64 . In a study carried out by Neelgund SM et al. ${ }^{18}$ patients undergoing hysterectomy had same age range, and mean age was found to be 45 years in one of the local studies conducted by Samina Saleem Dojki et al, ${ }^{19}$ which is in agreement with our study.

Leiomyomas are a frequent indication for hysterectomy. It is a smooth muscle tumour. The incidence of leiomyoma is about $20 \%$ in reproductive age group and increases with age..$^{20}$ In the present study, the commonest benign lesion was leiomyoma, present in $66 \%$ cases.
This relatively high frequency of leiomyomas in our study is consistent with studies conducted by Pathak $\mathrm{V}$ et al. ${ }^{14}$ and Baral $\mathrm{R}$ et $\mathrm{al},{ }^{3}$ both of whom found $49.78 \%$ and $48.6 \%$ frequency of leiomyoma respectively. In contrast lower values were observed in other studies. ${ }^{13,21}$

Nilima G. Sawke et al, found leiomyoma in $25 \%$ hystrectomy specimens in patients presenting with menorrhagia. ${ }^{22}$ Leiomyomas vary in size, may develop more than $11.4 \mathrm{kgs}^{23}$ In our study, the leiomyomas ranged from 0.5 to $14 \mathrm{~cm}$ in width and 0.5 to $10 \mathrm{~cm}$ in length.

Adenomyosis is another important finding in the hysterectomy specimens for abnormal uterine bleeding, defined as presence of endometrial glands and stroma deep within the myometrium. Non-invasive diagnosis of adenomyosis is difficult and invalid, diagnosis can only be confirmed after removal of uterus and its histopathological assesment. ${ }^{24}$ In present study adenomyosis was present in $21 \%$ of the cases. This is consistent with the study done by Neelgund SM et $\mathrm{al}^{18}$ and Sobande A A et al ${ }^{4}$ which reported adenomyosis in $21.7 \%$ and $22.7 \%$ of the cases respectively.

Twenty five cases (25\%) of endometrial hyperplasia were observed in this study. Nearly same findings were reported in a study by Ojeda et $\mathrm{al}^{25}$, but in contrary to it in a study by Isaoğlu $U^{26}$ endometrial hyperplasia was found lower than that reported in the present study.

Hormonal imbalance was an important finding on histopathology, after endometrial hyperplasia. Hormonal imbalance was reported in $21 \%$ of the cases in our study. Same was reported in a study conducted by Parveen Azim et $\mathrm{al}^{27}$ and $27 \%$ by Abid $\mathrm{M}$ et al. ${ }^{28}$

Chronic inflammation of cervix was observed as frequently prevailing microscopic finding, in about $75 \%$ of the cases in present study. Another $24 \%$ had squamous metaplasia with chronic cervicitis. Mild dysplasia with chronic cervicitis was present in one case only. Other studies have also reported high incidence of chronic cervicitis in hysterectomy specimens. ${ }^{13}$ 


\section{CONCLUSION}

Women in whom hysterectomy was undertaken were aged between 30-55 years, with maximum no. of cases (72\%) between 41-50 years. The commonest presenting complaint was menorrhagia present in $58 \%$ of the cases. Leiomyoma was the most common myometrial pathology, found in $66 \%$ of the cases, followed by adenomyosis present in $21 \%$ of the cases. Endometrial histology showed hyperplasia in 25\% of cases, hormonal imbalance in $21 \%$, pressure atrophy in $11 \%$, atrophic endometrium in $6 \%$, cystic atrophy in $2 \%$ while acute and chronic endometritis in $1 \%$ and $2 \%$ of cases respectively. Regarding cervix, cervicitis was frequently observed finding in about $75 \%$ of the cases.

Hysterectomy specimen should be assessed histopathologicaly to confirm pre-operative diagnosis and ensure better postoperative management.

\section{Copyright@ 26 May, 2019.}

\section{REFERENCES}

1. Baskett TF. Hysterectomy: evolution and trends. Best Pract Res Clin Obstet Gynecol 2005; 19:295-305.

2. Chris Sutton. Hystrectomy: A historical perspective. Bailliere's Clinical Obstetrics and Gynaecology 1997(3); 11:1-22.

3. Baral R, Sherpa P, Gautam D. Histopathological analysis of hysterectomy specimens: One year study. Journal of Pathology of Nepal 2017; 7:1084 -6.

4. A.A.Sobande et al,. Elective Hystrectomy: A clinicopathological review from Abha catchment area of Saudi Arabia. WAJM 2005; 24:31-35.

5. Bongers MY, Moi BW, Brolmann HA. Current treatment of dysfunctional uterine bleeding. Maturitas 2004; 47:159-174.

6. BhatS, BhatN, NiyazI, Wani R. A2 yearhistopathological audit for non-oncological hysterectomies in a tertiary care hospital. Int J Reprod Contracept Obstet Gynecol. 2017; 6:3260-3.

7. Maresh MJ, Metcalfe MA, Mcpherson K. The value national hysterectomy study: Description of the patients and their surgery. Br J Obstet Gynaecol 2002; 109: 302-12.
8. Sait K, Alkhattabi M, Boker A et al. Hysterectomy for benign conditions in a University hospital in Saudi Arabia. Ann. Saudi med 2008; 28(4):282-6.

9. Spilsburg K, Semmens JB et al. Persistent high rates of hysterectomy in Western Australia: A population based study of 83000 procedures over 23 years. BJOG 2006; 113(7):804-9.

10. Subrata $\mathrm{P}$ et al,. A retrospective clinico-pathological study of hysterectomy cases in a tertiary care hospital in India a review of 950 cases. Bangladesh Journal of Medical Science 2018; (1); 88-89. DOI: http:// dx.doi.org/10.3329/bjms.v17i1.35287

11. F. Nausheen, J. Iqbal, F. A. Bhatti, A. T. Khan, and S. Sheikh. "Hysterectomy: The patient's perspective," Annals of Gynecology 2004; 10:339-341.

12. Mc Pherson $\mathrm{K}$ et $\mathrm{al}$,. Severe complications of hystrectomy; The Value study. BJOG, 2004july; 111(7); 688-94,

13. Harshal A. Patil et al,. Histopathological findings in uterus and cervix of hysterectomy specimens. MVP Journal of Medical Sciences, 2015; 2(1):26-9.

14. Pathak V, Singh P, Tripathi A. Retrospective analytical study of total abdominal hyeterectomy for benign gynaecological conditions. Int J Reprod Contracept Obstet Gynecol 2017; 6:1596-603.

15. Verma D, Singh P, Kulshrestha R. Analysis of histopathological examination of the hysterectomy specimens in a north Indian teaching institute. Int $\mathrm{J}$ Res Med Sci 2016; 4:4753-8.

16. Kanwardeep Kaur Tiwana et al. Histopathological Audit of 373 Nononcological Hysterectomies in a Teaching Hospital. Hindawi Publishing Corporation Pathology Research International Volume 2014, Article ID 468715, 5 pages.http://dx.doi.org/10.1155/2014/468715

17. Ottawa: Canadian medical association; 2004. OECD Health Data 2003; 5-7.

18. Neelgund S, Hiremath P. Analytical study of hysterectomies. Int J Reprod Contracept Obstet Gynecol 2016; 5:2307-11.

19. Samina Saleem Dojki and Alia Bano. Outcome of total laparoscopic hysterectomy. Journal of the College of Physicians and Surgeons Pakistan 2018; 28 (6): 427430.

20. Jeffcoate's Principles of Gynaecology 7th international edition Kumar P, Narendra Malhotra; 2014:490. 
21. Amin A, Ali A, Amin Z, Sani FN. Justification for hysterectomies and frequency of histopathological lesions of hysterectomy at a Teaching Hospital in Peshawar, Pakistan. Pak J Med Sci 2013; 29(1):170172. doi: http://dx.doi.org/10.12669/pjms.291.2509.

22. Nilima G. Sawke, Gopal Krishna Sawke, and Hanisha Jain. Histopathology findings in patients presenting with menorrhagia: A study of 100 hysterectomy specimen. J Midlife Health. 2015 Oct-Dec; 6(4): 160163.doi: 10.4103/0976-7800.172299.

23. Baris Mulayim. Unaware of large leiomyoma: A case report with respect to unusual symptoms of large leiomyomas. Ann Med Surg 2015 Dec; 4(4); 431-433.

24. Levgur M. Diagnosis of adenomyosis. A review. J Reprod Med 2007; 52:177-93.
25. Ojeda VJ. The pathology of hysterectomy specimens. Z Med J. 1979; 89:169-71.

26. Isaoglu $U$. The evaluation of diagnosis in specimens of hysterectomy. Abant Med J. 2013; 2(2):941-943.

27. Parveen azim, Muhammad Mumtaz khan, Naveed sharif et al,. Evaluation of abnormal uterine bleeding on endometrial biopsies. Isra Med J Sep- Dec 2011; 3 (3):84-8.

28. Abid $M$ et al, Clinical Pattern and spectrum of endometrial pathologies in patients with abnormal uterine bleeding in Pakistan: Need to adopt a more conservative approach to treatment. BMC Women' Health. 2014; 14:132.

\section{AUTHORSHIP AND CONTRIBUTION DECLARATION}

\begin{tabular}{|c|l|l|}
\hline Sr. \# & Author(s) Full Name & \multicolumn{1}{|c|}{ Contribution to the paper } \\
\hline 1 & Aisha Rashid & $\begin{array}{l}\text { Designing the project, Data collection, } \\
\text { analysis, Literature review. } \\
\text { Data analysis, Literature review, Final } \\
\text { approval. } \\
\text { Data analysis, Literature review, } \\
\text { Manuscirpt writing. }\end{array}$ \\
\hline 3 & Sabigature \\
\hline
\end{tabular}

